\title{
Generalized congestion of power systems: insights from the massive blackouts in India
}

\author{
Yusheng XUE ( $₫)$, Shijie XIAO
}

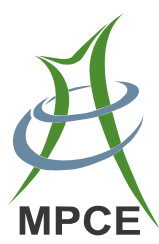

\begin{abstract}
The Indian power system underwent two separate massive blackouts on 30th and 31st of July 2012. These blackouts exposed a series of inherent problems underlying the power system of India, such as its generation planning, transmission planning, grid infrastructure, management systems, primary energy resources, environmental constraints, electricity market, and information technology, which together aggravate the massive blackouts. These factors which affect the adequacy and security of the power supply in a similar manner as the transmission congestion of physical grids does, can be called by a generic term as generalized congestion. Competitive manipulations and "game-playing" between various interested parties further intensifies these congestions. Here, from the perspective of generalized congestions, the paper reflects the inevitability of India's massive blackouts, discusses occasional effects of trigger events, inherent evolution law of blackouts and the enlightenment on power industry in China, and explores risk control measures to defend blackouts in China. The positive role of strong smart grid in insuring energy and environment security is highlighted.
\end{abstract}

Keywords Energy security, Power congestion, Multidomain interaction, Complex system, Domino effect, Comprehensive defense, Risk control

Received: 1 February 2013/Accepted: 6 May 2013/Published online: 13 August 2013

(C) The Author(s) 2013

Y. XUE, S. XIAO, State Grid Electric Power Research Institute, Nanjing 210003, China

$(\triangle)$ e-mail: xueyusheng@sgepri.sgcc.com.cn

S. XIAO

e-mail: xiaoshijie@sgepri.sgcc.com.cn

\section{Introduction}

At about 2:30 a.m. (Indian Standard Time, IST) on the 30th July, 2012, the $400 \mathrm{kV}$ Bina-Gwalior power line in the state of Uttar Pradesh in India was tripped. This accident initiated a cascade of outages and subsequently led to the collapse of the country's entire northern grid. The massive blackout hit New Delhi and nine states (including Madhya and Uttar Pradesh), affected 370 million people, and forced $35.67 \mathrm{GW}$ of load demand (around $18 \%$ of the total load demand of India) to be taken offline. During the blackout, railway systems were shut down, the subway service in New Delhi was also stopped, and the urban transportation systems were paralyzed. More severely, the civil water supply was interrupted and more than 200 miners were trapped underground [1]. The emergency forced the electricity suppliers to transfer power from eastern and western India and also purchase additional power from Bhutan. These approaches quickly restored the power supply. As of 13:00 p.m. and $16: 30$ p.m. on 30 July $2012,70 \%$ and $85 \%$ of the load demand was restored [2].

The next day (31st of July, 2012), the system failed again at 13:05 p.m. IST. A massive blackout again collapsed the northern grid. In addition, the eastern and northeastern grids were also affected. Twenty of India's 28 states were hit and $50 \mathrm{GW}$ of load demand was affected. Approximately 670 million people (nearly half of the national population) were without power $[3,4]$.

These two blackouts are the largest in history regarding the number of people affected, and produced huge direct economic losses and profound social impacts. According to the Planning Commission of the Indian Government, these blackouts are expected to reduce India's growth rate by $1.2 \%$ and negatively affect potential foreign investment in India [4]. 
Power Miniser Sushil Kumar Shinde, who was promoted to Minister of Home Affairs exactly on the day of the blackout, stated that the long-term overdraw of power by some states may be responsible for this massive accident. He, however, did not explain why such severe overdraw was not prevented. The government investigation report summarized the causes of the blackouts, which include: poor grid infrastructure, overloading of interconnection lines, mal-operations of protection systems, the absence of authoritative top-level to state-level control, etc. Suggestions were also given by the report to encourage better coordination between the top and region level controls, forced primary frequency regulation and effective underfrequency and under-voltage load shedding, etc. [5].

Similar to India, China is experiencing a rapid economic growth and facing a series of challenges such as lack of energy, strong dependence on imported fossil fuels, transition of economic growth modes, environmental pressures, as well as rapid changes in electric power, power grids, and load demand. What can China learn from these events in India that will help prevent similar events from occurring in China's power grids? This attracts attentions of Chinese researchers from various fields [6-8].

From the perspectives of macroenergy [9] and generalized congestions [8], the paper analyzes the causal factors (inevitable or accidental) underlying these massive blackouts, and the evolution processes; it also emphasizes the important role of strong smart grids and the multi-spacetime-scale cooperative blackout-defense system in the risk reduction for power, energy, and environment systems.

\section{India and its energy systems}

Currently, India is the tenth largest economy in the world and the third largest in Asia, following China as one of the biggest developing countries (along with Brazil). With booming high technology industries and software outsourcing, India has become the "world's office" and fostered a large high-tech workforce (second only to the USA). In the past two decades, the gross domestic product (GDP) of India has grown at an average annual rate of $7 \%$. Even during the global financial crisis (2009-2011), the country still reached a remarkable average annual GDP growth of $7.8 \%$ [10].

However, without any top-level design, these achievements have been supported primarily by new technologies, while traditional industry sectors (e.g., manufacturing) and infrastructure construction have remained largely undeveloped. According to The Global Competitiveness Report 2012-2013, published by the World Economic Forum in 2012 , the quality of overall infrastructure of India ranked 87 out of in 144 countries: lower even than Sri Lanka and
Botswana. As reflected by the report, the weak and dated infrastructure and the longstanding lag in development of electric power generation and transmission grid in India has become a bottleneck limiting economic growth. The severe shortage of power generation capacity has been causing shortfalls in power and power outages, and the lack of transmission capacity has been creating power transmission difficulties for existing power stations and also leading to blackouts caused by failures. The risk of failures has been increased due to the lack of investment, information share and the capability to handle failures limited by poor on-line precautionary information and control technologies.

From the perspective of power generation, the capacities of India and China were similar in the 1960s. In May 2012, however, the total installed capacity of India $(200 \mathrm{GW})$ was only around $20 \%$ of that in China [3]. In 2011, the per capita electricity production of India was only $26.4 \%$ of the global average. Clearly, this severe power shortage cannot support balanced regional and economic development or sustained growth [11]. Furthermore, it cannot even insure basic social justice and stability. As an example, in 2011 , around $25 \%$ of the population of Indian $(6 \%$ of the urban citizens and $33 \%$ of the rural citizens) had no access to electricity [11].

From the perspective of power transmission, the lack of regional interconnection has limited the optimization of normal operations, and also the efficiency of emergencyresponse measures. Without stable water and electricity supplies, it is difficult to attract foreign investment into manufacturing industries, thus further limiting the development of basic industries and initiating a vicious cycle.

The main energy sources in India are coal (concentrated in eastern India) and hydropower (primarily in northern and northeastern India), both ranked fifth in the world. The per capita energy resources of India are lower than those in China. Fortunately, a large fraction of the coal fields in India are suitable for surface mining, and this has translated into relatively low coal and thus low electricity costs. However, other complicated issues in this country (e.g., environmental protection, land requisition, and gameplaying between interested parties) have limited the efficiency of coal mining. As a result, approximately $10 \%$ of the power generation capacities have been left idle because of coal shortage [3]. Other electric power in India is generated from nuclear power, oil, natural gas, and renewable energy sources in a small scale. India's total domestic energy production failed to meet its energy consumption. According to a statistics of $2011,24.8 \%$ of the coal, $75.0 \%$ of the petroleum, and $24.5 \%$ of the natural gas consumption in India were imported from other countries. If the Indian government further increases the scale of energy import, it would lead to even larger financial 
deficits and deepen the credit crisis of the government. If power suppliers relay on these costly imported primary energy sources, it will inevitably create severe financial losses and even bankruptcy. Consequently, there has been a lack of motivation for constructing new power plants. As a result, in early July of each year (before the start of the rainy season), the power shortage reaches up to $18 \%$. Power outages and usage limits become a normal state of affairs in New Delhi, with some communities even experiencing up to $8 \mathrm{~h}$ of power shortage daily.

In 2011, thermal and hydropower plants generated $80.8 \%$ and $14.9 \%$, respectively, of the total power generation in India. Coal, natural gas, and diesel power plants contribute $82 \%, 17 \%$, and $1 \%$ of total thermal power generation, respectively. The load centers and heavily populated areas are located in the northern, southern, and western regions [11]. Accordingly, electric power is transmitted primarily from the east to the west, and supplemented by north-to-south transmissions. The power transmission grids of India consist of five regional systems: the northern grid, eastern grid, northeastern grid, western grid, and southern grid. The first four systems form an interconnected wide-area synchronous AC grid. The last system (i.e., southern grid) is interconnected with the eastern and western grids via DC transmission lines or back-to-back DC transmission systems. Overall, the Indian power system operates in a "weakly interconnected" backto-back DC transmission mode similar to that of Japan. This mode, however, allows only limited power exchange, thus adversely affecting the level of resource sharing and emergency assistance. Additionally, because of the lack of centralized management mechanisms, the coordination for different responses during accident management is difficult. Consequently, local accidents can easily result in large-scale blackouts [3].

\section{Inherent factors underlying the massive blackouts}

Power system reliability includes two aspects: adequacy and security [12]. The adequacy of a system reflects its capability to provide power over various time scales and, thus, it includes two sub-elements: adequacies in power generation and transmission. The security reflects the ability of a power system in tolerating disturbances without failure. Lack in power generation adequacy, transmission adequacy, or security could lead to blackouts (local, regional, or bulk systems).

Routine occurrence of blackouts reveals inherent problems and structural flaws in the Indian electric power industry. At a macroscopic level, these include: longstanding lag in infrastructure development following policy mistakes (especially the lag in electric power grid development, lack of strong main grids, and disorganized management), escalating shortages of available generation capacity resulting from poor policy reinforcement, severe congestion of power transmission determined by the excessive division of administrative systems, and the conflict between the original intention of excessively market-oriented structure and the reality of a strong market influence [13].

As a federal country, the electric power industries of India are regulated by both the central (i.e., national) and local (i.e., state) governments. At the national level, the Power Grid Corporation of India Ltd. controls the national power transmission facilities, and it is responsible for the operation of the centrally-owned power plants and large independent electric power generation companies. At the state level, the power department of each state is responsible for the state-owned power plants and independent power companies in the state, and power distribution is provided through co-ordination between the state power department and private power companies. Under this hierarchical system, the power management of the central government relies on the chief ministers of individual states and thus is usually unable to control their localinterest-oriented behaviors, which are potentially harmful to the national power system as a whole.

The grid management system of India consists of four hierarchies: national, regional, state, and local departments. Each hierarchy represents different interested parties without effective mechanisms to coordinate them across hierarchies. This highly divided management results in poor, inefficient, and even incorrect policies and administration. For example, each state conducts its own power system planning and thus, inevitably, leads to repetitive facility construction. The focus of the central government also varies between oil-fired power, nuclear power, and green energy without a consistent direction. Inevitably, the outcome of infrastructure investment is poor. In addition, power management departments frequently yield to political pressure to price electricity at abnormally low levels. Free electricity for farmers provided for irrigation is widely used for other illegal purposes. The electricity losses in India are around $24 \%-40 \%$ because of network losses and consumer theft [14].

With the absence of a centralized power management system, the states frequently disregard orders issued by the national management department. During normal operation, individual states operate and compete only according to local interests, thus preventing improving the overall efficiency of the grids and even creating overload and other security risks. In cases of power shortage, individual states draw power from main grids beyond acceptable limits. After detecting such overdraw, the national management center is not permitted to directly intervene and can only 
issue penalty notices via the Central Electricity Regulatory Commission. Naturally, in cases of emergency, each state acts according to its own interest without considering the associated impact on the whole power system. This divided management system is barely operational even under normal conditions, and can be expected to be ineffective and even counter-effective under emergencies. Under this decentralized management system without central coordination, it is inevitable that there is no information sharing system, and thus no security and stability on-line quantitative analysis and control decision support mechanisms. Consequently, it is impossible to coordinate preventative controls and emergency controls, let alone self-adaptive protective actions and periodical on-line refreshing of response plans for potential accidents. Particularly, during the restoration control, this scattered regulation system is not capable of assessing the risk of cascading massive blackouts, and thus resulted in the second, even larger blackout on the 31st of July 2012.

From the perspective of grid structure, the power grids of India lack integrated blackout-defense systems at the top level, and have no self-adaptive plans for accidents and the required supporting control mechanisms. The grid operators also lack awareness of risk management, and prearranged plans to deal with power system blackout. Therefore, in case of cascading failures (and especially severe natural disasters), a domino-like power grid collapse is inevitable. During the subsequent restoration control, the grids are inherently susceptible to another larger-scale blackout, as seen on the 31st of July 2012.

The lessons from these two massive blackouts reveal that the scattered grid management in India's excessively privatized environment failed to meet the demands for electric power brought on through the rapid economic growth of India. Inappropriate and incorrect policies have impeded the construction of the required infrastructures, especially electric power plants and grids. In addition, various other issues (e.g., primary energy, environmental factors) have produced generalized congestion, thereby routinely forcing available generation capacity and transmission capacity into crisis conditions. Even during regular operation, the grids have been constantly operating with severe power shortages and thus severely arresting the economic growth. Arrested economic growth, in turn, has restrained investment into infrastructure construction, thus forming a vicious cycle.

Economic systems closely interact with physical systems; therefore, economics and security should be coordinated based on risk-management strategies [15]. Without the toplevel design in a strict manner, a private market environment containing game-playing behaviors of all interested parties will eventually destroy the security of the power supply. In 2002, India explicitly emphasized the leading roles of private power companies in power infrastructure construction and power industry reform. The positive effect of this excessively privatized mode on the development of power industry now appears overestimated.

Against this background, power systems constantly operate under inappropriate conditions. Any initial event may trigger a domino-like collapse as long as the system remains operating close to its stability limit. Situations fueled by human-made errors present an even greater danger. Given the inherent factors in the Indian power system, even without the actual trigger of the first massive blackout (i.e., power line trip), similar massive failures are bound to occur.

\section{Accidental factors in the blackouts}

Aside from inherent issues, large disasters are usually initiated by accidental events which are subsequently propagated and amplified via a series of cascading failures and human errors [15]. Although the massive blackouts hurt the Indian economy, they also revealed the fundamental problems in the power system and could serve to prevent larger disasters in the future. However, if the system is left operating at the verge of collapse, its failure may produce even more devastating effects if triggered (e.g., by extreme natural disasters). This inference also is true for other systems, such as the recent rainstorm disaster that Beijing's drainage system faced.

These two blackouts are generally believed to be related to the dry climate, which reduced the hydropower generation and increased the electricity demand for irrigation. However, it seems surprising that the failure occurred at midnight, when the grid load is typically low. One explanation is that, in order to satisfy the residential electricity demand, the local governments limited industrial power use before 22:00 p.m., thus turning midnight into a peak period [16]. If this was true, it would be surprising that the management departments took no corrective actions even after emergency measures were over regulated.

\section{Caution and enlightenment}

For a modern economy, a massive blackout may involve financial losses exceeding the economic benefits resulting from market competition. Furthermore, it could even endanger national and social security. However, on the positive side, human society develops through surviving disasters and setbacks, and learning from the two massive blackouts may help prevent more devastating accidents. Similar to India, China is a developing country with a large population and energy demand. Moreover, both countries 
need long-distance high-capacity electric power transmission because of the mismatch between the locations of energy sources and load demand. Therefore, the massive blackouts in India also revealed potentially important and alarming information for China. The power shortage and grid structural fragility in the Indian grids can also be found in the Chinese power system. If China does not reduce its dependence on fossil fuels, or its power transmission system does not comply with the nature of power flow, power supply may become a major bottleneck for its economic growth again.

Consistent with experiences from other similar accidents worldwide, the two massive blackouts revealed critical information. First, various factors related to the power transmission system should be reexamined under a unified framework, including the power industry structure, marketing strategies, regulations, planning and design, simulation, information systems, operation management, control techniques, R\&D investment, and employee training. Second, the construction of strong smart grids should be expedited. The planning, construction, management, and operation of these smart grids must be conducted under a unified framework. In addition, urban and rural grids, power transmission and distribution, and grid operation management must be integrated and controlled by a centralized agency.

The mechanisms of evolution between the two blackouts deserve careful attention. Surprisingly, the second blackout (more massive) appeared when the grids were almost restored back to normal following the first blackout. The underlying mechanisms of this failure should be traced and analyzed. This surprising "second-wave" strike demonstrated the necessity of a coordinated management system, and also indicated the importance of an effective coordination between preventive control, emergency control, corrective control, and restoration control.

Strong infrastructure facilities usually insure reliable power supply under normal conditions or general failures. However, during extreme natural or human-made disasters, well-designed management and risk-defense systems are required. If the improvement of the blackout-defense system was abandoned, even a highly strong power system can still become susceptible to failures, as was the case of the US-Canada 8.14 Blackout [15].

Because of the lack of blackout-defense framework at the top level, the power system managers failed to take appropriate measures to stop a domino-like failure at different stages during the evolution of the two blackouts in India. First, the planning and construction of infrastructure facilities should insure sufficient generation and transmission adequacy. Second, smart control is required during the operation of the system, such as self-adaptive preventive control for normal operation and self-adaptive emergency control after responses to failures have been initiated. The demand-side management should consider both the economic performance and the system security. Third, appropriate risk awareness must be incorporated in restoration control to prevent consecutive cascading blackouts.

In addition, the power industry structure and its management should meet the requirements of economic growth. Given the complexity of power security, policy makers should not overemphasize marketization while neglecting the adverse effects of market-driven competition, decentralized planning, construction, and management on the adequacy and security of power systems. Although security and economics may seem to conflict, they are completely united regarding overall economic performance. Therefore, these two aspects should be coordinated under the concept of risk management.

The goal of the electricity reform in China is to create a fair, open, orderly, and competitive electricity market, thereby optimizing grid regulation, improving the efficiency of the power industry, and promoting the sustainable development of the electricity industry. In a competitive market, the basic role of the power grid is to provide a fair and open platform. This central task of this platform is to provide open and unbiased market entrance for market participants. However, as power transmission and distribution are naturally monopolized services, simply introducing market competition to the power networks may not be practical or economical. Globally, power industry reforms in many countries were always initiated with high awareness of the unique techno-economic characteristics of this industry. Accordingly, the economic gains of reform were achieved primarily by introducing competition to the power generation and retail sectors while keeping the power transmission and distribution sectors regulated by the governments.

Regarding the reform of the power transmission-distribution services, different countries selected different reforming models (separated or integrated power generation and distribution services) according to their own conditions. Most countries choosing the separated generation and distribution mode is due to historical reasons. On the other hand, Russia and some states of Australia switched to the separate generation and distribution mode as a result of reform. However, in Russia, after a complete separation of power sectors (i.e., generation, transmission, distribution, sales, management, trading) in 2008, the country recently showed a tendency toward recombining the power transmission and distribution sectors. After market-oriented electricity reforms, France, Germany, Japan, South Korea, and most states (provinces) of the USA and Canada have decided to keep the original mode of integrated power transmission and distribution. In the European Union (EU), the Third EU Energy Legislative Package requires that, if the power generation and retail 
sectors have been effectively separated, it is not mandatory to separate other services from power transmission. Therefore, experiences in other countries or regions indicate that separation of transmission and distribution is not necessarily the only choice of reform. In fact, the massive blackouts in India demonstrated that developing countries typically is experiencing rapid economic changes that create great uncertainties for their power grids. For these countries, separated power transmission and distribution can pose severe risks to their power systems; excessive marketization is negative to top-level management for power system's security; scattered dispatch systems without any coordination mechanisms will fail to handle emergency accidents.

Compared with the separate model, an integrated power transmission-distribution network is ideal for optimizing the planning, construction, and operation of power systems. This integrated model is also suitable for meeting rapid growth demands, improving the operation efficiency, and optimizing resource allocation over the large scale. Even for developed countries without substantial growth in power consumption, the integrated model can also contribute to the power system security and disaster prevention capability.

Market competition is efficient in the power generation and retail sectors. In comparison, power transmission and distribution are naturally monopolized services: without economic conflicts but with similar modes of profit and regulation methods. Therefore, integrated transmissiondistribution networks can realize strong synergistic effects. Moreover, during rapid growth of electricity consumption, an integrated power transmission-distribution network is compatible with organized planning, construction, and operation of power systems. These organized activities allow timely response to the demands of rapid growth, improve the efficiency of the power systems, and optimize resource allocation over the large scale. Because of these obvious advantages, 137 of 150 developing or transition countries of the world maintain the integrated model. Even for developed countries with mature power systems which do not change very often, the integrated model provides advantages in security and disaster prevention capability.

Clearly, different power transmission-distribution structures are suitable for different stages of economic growth. China currently undergoes accelerated urbanization and industrialization, and thereby the separation of transmission and distribution is not an ideal model for the nation. In fact, the separated model may adversely affect the coordination of grids and substantially reduce their resistance to natural disasters and subsequent recovery, especially when a large amount of renewable energy is being integrated into the grids. In comparison, the Chinese power system (an integrated transmission-distribution system) has maintained a high reliability despite the fact that its grid is quite weak. During past natural disasters (e.g., earthquakes, ice storms), the Chinese power system has gained abundant experiences, both positive and negative. Therefore, introducing competition via opening power generation and retail, maintaining integrated transmissiondistribution, and improving the pricing system are the optimum solution for the Chinese electricity power industry.

If the emergency management and control strategies in a power system are independently made by isolated economic entities, or closely related controls (preventive, emergency, corrective, restoration) are performed by separate departments without global coordination, the power system control strategies are highly susceptible to disruption and may even intensify the impact of the initial natural disaster by manmade errors. The second wave of Indian blackouts is such a heartbreaking lesson, which is caused by severe overdraw of power during the restoration process after the first wave of blackouts on July 30 .

\section{Efforts of the Chinese electricity industry in preventing massive blackouts}

A strong and smart power system is the basis for power supply security and disaster prevention, and supports largescale power flow transferring and response to severe cascading failures. Accordingly, this requires coordinated grid planning, construction, management, and operation. It also demands the integration of power transmission and distribution networks, integration of grid operation management, and integration of urban and rural grids.

Based on the experiences of other countries, the Chinese electricity industry has developed and implemented an innovative strategy for creating strong smart grids [17]. The strategy involves using ultra-high voltage (UHV) grids as the backbone structure and emphasizes coordinated development of grids at various levels. Currently, the Chinese electricity industry stresses risk evaluation-analysis and management during grid operations, maximizing the effects of cross-region UHV grids in optimizing energy allocation, and upgrading demand-side management and lifecycle equipment management.

China has also innovated and extensively applied comprehensive defense techniques against massive blackouts, which has greatly improved the economy and security of its power system [18-20]. A Wide-Area Monitoring Analysis Protection-Control system (WARMAP) with full intellectual property rights has been developed in China and applied to $4 / 5$ of the provincial and national grids. Efforts are underway to achieve higher goals, including extending the range of data collection from the power system to the 
natural environment [21], extending the scope of coordinated control from normal grid conditions to extreme environments, upgrading the defense strategies from preplanned measures to active defense. Through these efforts, the Chinese power systems expect to achieve coordinated and optimized comprehensive defense for insuring the security and stability of bulk power systems and prevent external disasters or accidental fault from progressing to power system blackouts [22, 23]. And, building a global dispatch system is the only way to reach the goal of minimizing risks and losses.

\section{Strategies for reducing the risk of massive blackouts}

The two national power grid corporations (State Grid Corporation of China and China southern Power Grid) have been facing various challenges continuously during the power grid construction process. However, for quite some time no massive blackouts have occurred in China. Regardless of the process of future power reform, security is the top priority for the Chinese power system. Fortunately, as opposed to India, China currently does not face systematic power shortage. Therefore, the key task facing the Chinese power system is to optimize the power system dispatch and comprehensive blackout-defense system. To accomplish these tasks, many areas of operation should undergo continuous innovation and improvements, in areas such as the management structures, infrastructure facilities, preventive controls, emergency controls, corrective controls, and restoration controls. Furthermore, the macrosecurity perspective should be created based on the macroenergy perspective, key issues to be resolved include: coordinating primary energy with secondary energy and optimizing energy structures to improve total energy efficiency and support sustainable development; coordinating the planning and development among energy flows comprised of primary energy, generation, transmission, distribution and consumption; utilizing demand-side management and energy conservation measures as virtual generation, transmission and distribution resources; giving consideration to both real-time, short-time power balance and long-term reserve problems; studying system stability and adequacy under different scenarios considering highrisk events.

Small-probabilistic but high-risk events should be treated carefully. Although natural disasters are unavoidable, the influence of human-made errors should not be neglected [24]. To reduce the high risks associated with smallprobability events, a coordinated time-space comprehensive defense framework must be established from different dimensions of technology, planning, implementation, management, and public emergency response etc., focusing on state repairing, risk identification, information security and emergency management.

A national emergency-response system should be developed at the central government level to improve the ability of the whole society to deal with extreme natural disasters and human-made accidents.

The construction of UHV-based strong smart grids should be accelerated based on integrated planning, and the development of grids at all levels should be coordinated. In addition, the evaluation, analysis, and treatment of operational risks should be improved to maximize the capability of UHV cross-regional power systems in optimizing energy allocation. Moreover, the demand-side management and lifecycle equipment management should also be enhanced.

The grid should constantly improve its time-space coordinated defense systems against major blackouts. The risk information collection system should monitor natural (e.g., meteorological, geological, emergency-response equipment) and social information. Information systems should be improved and organized at various levels. These measures allow security, stability on-line quantitative analysis and decision-making. Defensive controls should be pre-planned for various accidents and disasters, and preventive and emergency controls should be coordinated. Self-adaptive protective mechanisms should be applied, and plans against various potential accidents should periodically be refreshed on-line for multiple time scale and multiple risk objective decision-making support. These strategies form comprehensive active defense mechanisms for large grids, avoiding the risk of power-related disasters.

In addition, safe and reliable equipment is also a key factor for a strong power grid. Governments should encourage the power equipment manufacturing industries to upgrade toward smart, advanced, and integrated manufacture via policies related to technology, products, and supply-chain cooperation. The power industry should promote the systematic application of equipment to localization, thereby increasing the reliability and preventing major blackouts.

Power systems are among the most complex systems created by humans, and a completely secure power system without blackout does not exist. Under compromised conditions, various factors (inadequate information, automation disruptions, and human-made decision errors) may create new disturbances to the power systems. Consequently, even a highly strong system could be destroyed when suffering a series of cascading attacks.

The key point of the problem is that, upon such crisis, actively ordered small-scale power outages should be initiated to prevent passive and unordered massive blackout. Therefore, it is valuable to study how to implement sufficient emergency and corrective controls under various emergency conditions to prevent subsequent domino-like 
failures. Even impossible to completely prevent accidents, the power system should take active low-cost actions to prevent a complete loss of control and thus reduce loss.

The power system is a critical element in the overall energy system and environmental security. Interactions between a power system and its external environment are shown in Fig. 1. It is also closely interconnected to other external elements. It is essential to maintain a smooth flow of energy, capital, and information for the power system, and to control its emission, and thereby to insure power, energy, and environment security. Consequently, these objectives are inevitably limited by multiple factors such as primary energy, pollutant emission, technical support, and multi-party game-playing.

The power system is intrinsically a monopolized industry which takes the power market as its mode of operation. Consequently, regulation is necessary. However, inappropriate regulation could profoundly damage the power system. Experimental economic modeling incorporating physical and economic models are required for supporting the decisions of regulation policymakers.

The management of the power system requires major attention. The management department should improve information mining and publication, establish process controls based on sufficient information, and allow early warnings at various time scales. Frequently, the management system responds to accidents according to preplanned strategies while lacking flexibility in dealing with emergencies. It is thus essential to understand the patterns and mechanisms of the evolution of accidental disorders to disasters. Correspondingly, based on such understanding, the management system can automatically switch between control modes, accomplish the self-organization of functions, and coordinate and optimize responding strategies during different stages of an accident's evolution.

The communication network safety and information reliability have become key issues for the defense system.
It is essential to develop techniques for maintaining core control when the accident endangers the communication network itself. Techniques are required for evaluating the integrity, timeliness, and value of wide-area measurement and simulation data. It is also necessary to develop analysis and control techniques for conditions with incomplete wide-area data. Moreover, it is valuable to develop information mining techniques for dynamic wide-area data and investigate in-depth data processing and effective data expression.

A strong smart grid is a critical element of a defensive framework for energy and environmental security [25, 26]. It also expedites and maximizes the integration of renewable energies, changes the means of energy transfer, supports wide-area allocation of energy resources, and increases the proportion of electricity in final energy consumption. For example, the construction of smart charging networks for electric vehicles and the changes in the manner of electricity consumption stimulates the effective use of clean energies, eventually contributing to energy conservation and emission reduction.

\section{Challenges and missions}

The electric power industry plays a key role during the transition of the energy industry to a sustainable and lowcarbon future. Because of the mismatch between the locations of energy resources and load demand, a successful transition of China's electric power industry requires a strong and reliable bulk power grid to optimize energy resource allocation over the large scale.

The reliability of a power system is affected by disturbances from its external sectors. Vice versa, the security and stability of the power system will also influence these external sectors. Therefore, it is critical to consider the interactions between the power system and its external

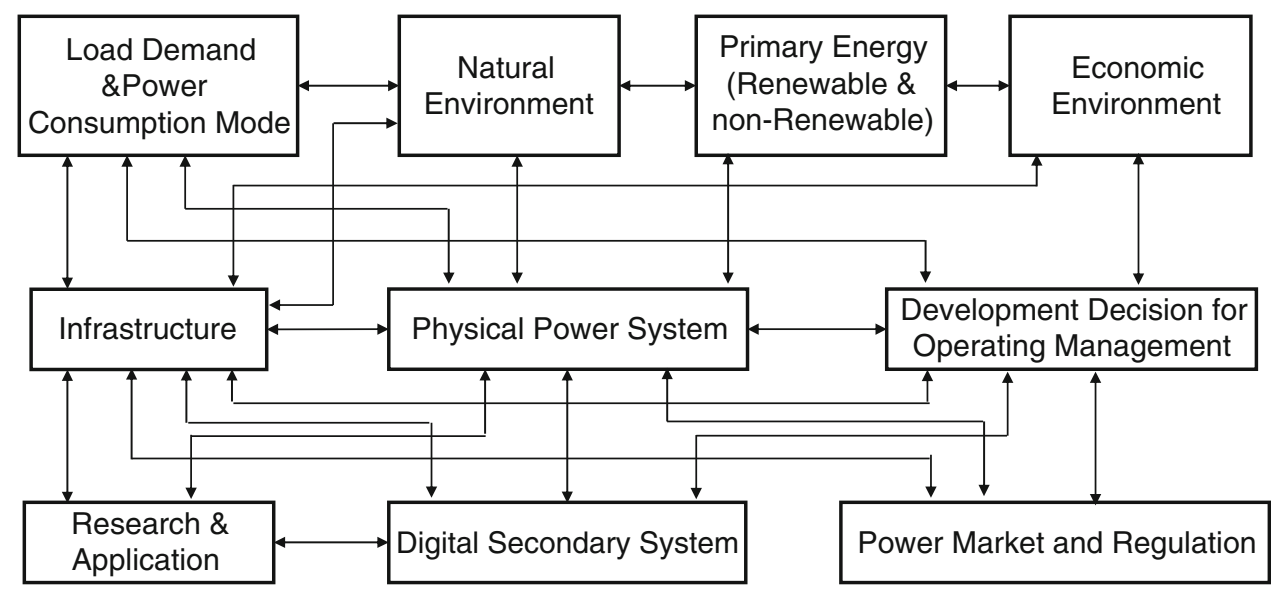

Fig. 1 Interactions between a power system and its external environment 
sectors and address the adequacy and security of the macroenergy system.

The power system management should conform to the intrinsic requirement of electricity flow (i.e., constant balance), and correspondingly maintain the management mechanisms for integrated planning, integrated dispatch, and coordinated control. Additionally, the electricity industry should understand the effects of market factors on power supply reliability, balance security, and economic performance under the principle of a risk-management concept.

At the national level, the central government should plan a global emergency-response system to coordinate the disaster defense of various sectors. The responsibilities of various emergency-response departments and their interfaces must be clearly defined, and mechanisms must be established to allow their rapid and coordinated activities. Importantly, the resistance of the whole society to natural disaster and human-made accidents should be upgraded. Information sharing mechanisms are required to allow effective communication of early warning and information essential for decision-making between industrial sectors.

The Chinese power system is undergoing strong growth in power consumption and rapid changes in transmission and distribution networks. Under these complex conditions, centralized management, centralized dispatch and an integrated transmission-distribution network are critical for system security. Division of the power transmission sectors based on simply following the market rule of other products will create great risks for the system, at least during the current rapid growth period. At the present stage, division of electricity transmission and distribution networks or centralized dispatch cannot produce economic benefits, as is clearly indicated by these massive blackouts in India.

The Chinese electricity industry has created innovative techniques for quantitative security and stability analysis, early warning, and decision optimization. The industry has also developed and successfully applied a blackout-defense framework. Despite these achievements, the industry should further enhance its ability to deal with cascading natural disasters and complicated uncertainties. Importantly, the industry should establish a more effective emergency-response system to insure quick, well-organized, and efficient activities during emergencies.

To continue its success, the Chinese electricity system should aim to achieve a series of higher goals. It should extend the wide-area data collection from the electricity system alone to include natural and social sectors. Thus, it can provide opportunities for forecasting accidents (e.g., hail, typhoons, lightning), foreseeing changes in primary energy and environmental conditions, and allow more time for response planning, material allocation, and the arranging of repair forces. Moreover, the system should allow dynamic evaluation of the risks in the communication networks (both the electricity system and the public communication system) and their potential impacts on its blackout defense. It should extend the range of effective early warning from minutes to hours and increase the number of early warning targets from single failure risks to cascading failures risks. The system should adopt selfadaptive decision-making strategies to minimize the scale of power outages, as well as the duration (via restoration control [27]). Finally, it should prevent small-probabilistic events from progressing into large-area public crises and promote restoration of services through appropriate emergency responses.

\section{Conclusion}

Malicious pleasure and naive optimism are unwise attitudes toward the massive blackouts in India. The scenarios during those blackouts should be investigated and the management system and blackout defense of the Chinese power system should be correspondingly analyzed. Experiences from the massive blackouts can improve confidence in the Chinese power system but also reveal weakness in that system. In fact, the experiences show that the Chinese power system also has substantial risks in infrastructure facilities, management structure, and emergency responses. It indicates that the Chinese electricity industry should upgrade its performance and reliability through constant innovation. Learning from these experiences may provide valuable insights for security and healthy development of the Chinese electricity industry as well as the whole Chinese economy.

Comprehensive defense of high risks associated with small-probability accidents must conform to the principle of a united overall energy system [9]. A coordinated multidimensional time-space comprehensive defense framework must be undertaken using a variety of aspects such as technology, planning, implementation, management, and public crisis response preparation. The traditional but effective strategy of "three-defense-lines" should be extended to insure effective and coordinated control of small-probability but high-risk emergency events.

China is constructing strong smart grids, promoting the use of distributed generation, and encouraging electricity storage and micro-grid development. The Chinese electricity system is on the way of improving the adequacy and security of information input, insuring the robustness of decisions, and supporting the availability of output information and transparency of disaster information. The system is also developing mechanisms for automatic on-line preplan refreshing to insure organized responses after 
emergencies, thereby effectively controlling small-probability high risks events and insuring power supply for critical load demands under extreme disasters.

Open Access This article is distributed under the terms of the Creative Commons Attribution License which permits any use, distribution, and reproduction in any medium, provided the original author(s) and the source are credited.

\section{References}

[1] The massive blackouts in India-the largest blackout in the world. http://old.china5e.com/special/show.php?specialid=575 (in Chinese). Accessed 01 Aug 2012

[2] India had to purchase electricity from Bhutan, the power supply in New Delhi has been completely recovered. Xinjingbao. http:// world.people.com.cn/n/2012/0802/c157278-18656175.html (in Chinese). Accessed 02 Aug 2012

[3] Xue Y (2012) The domino effect in the massive blackouts of India. http://news.xinhuanet.com/coal/2012-08/07/c_123541585.htm (in Chinese). Accessed 07 Aug 2012

[4] The massive blackouts awakened India. http://finance.sina.com. cn/review/sbzt/20120802/103312739109.shtml (in Chinese). Accessed 02 Aug 2012

[5] Enquiry Committee (2012) Report of the enquiry committee on grid disturbance in northern region on 30th July 2012 and in northern, eastern \& north-eastern region on 31st July, 2012. http://www.powermin.nic.in/pdf/GRID_ENQ_REP_16_8_12.pdf. Accessed 16 Aug 2012

[6] Fang Y (2013) Application of emergency control to reduce risk of system collapse triggered by power transmission interface tripping: thinking on the India power blackouts. Automat Electr Power Syst 37(4):1-6 (in Chinese)

[7] Zeng M, Li N, Dong J et al (2012) Key technologies of power grid operation and management based on philosophy of general security: a view of blackout in India. Automat Electr Power Syst 36(16):9-13 (in Chinese)

[8] Tang Y, Bu G, Yi J (2012) Analysis and lessons of the blackout in Indian power grid on July 30 and 31. Proc CSEE 32(25): 167-174 (in Chinese)

[9] Liu Z (2012) Electric power and energy in China. China Electric Power Press, Beijing (in Chinese)

[10] Yang K, Luo H (2012) The most severe blackout in India's history highlights the risk of its fast-developing economy supported by dated infrastructure. Meirijingjixinwen. http://finance. qq.com/a/20120802/000387.htm (in Chinese). Accessed 02 Aug 2012

[11] Insights of India's blackouts: the development of electric power industry should precede the national economy. http://www. indaa.com.cn/dwxw2011/dwyw/201208/t20120805_1101677.html (in Chinese). Accessed 05 Aug 2012

[12] Kundur P (2001) Power system stability and control. McGrawHill, New York

[13] Xue Y, Li T, Yin X et al (2010) A research framework for generalized congestions and market power. Automat Electr Power Syst 34(21):1-10 (in Chinese)

[14] India recovered its electric power supply with difficulty. Dushikuaibao. http://www.ccei.org.cn/show_trz.asp?ID=90979 (in Chinese). Accessed 02 Aug 2012

[15] Xue Y (2003) The way from a simple contingency to systemwide disaster-lessons from the eastern inter connection blackout in 2003. Automat Electr Power Syst 27(18):1-5 (in Chinese)

[16] Romero J (2012) Lack of rain a leading cause of Indian grid collapse. http://spectrum.iee.org/energywise/energy/the-smartergrid/disappointing-monsoon-season-wreaks-havoc-with-indiasgrid/?utm_source=techalert\&utm_medium=email\&utm_campai gn $=080212$. Accessed 31 July 2012

[17] Xiao S (2009) Consideration of technology for constructing Chinese smart grid. Automat Electr Power Syst 33(9):1-4 (in Chinese)

[18] Xue Y (2006) Space-time cooperative framework for defending blackouts. Part I: from isolated defense lines to coordinated defending. Automat Electr Power Syst 30(1):8-16 (in Chinese)

[19] Xue Y (2006) Space-time cooperative framework for defending blackouts. Part II: reliable information, quantitative analyses and adaptive controls. Automat Electr Power Syst 30(2):1-10 (in Chinese)

[20] Xue Y (2006) Space-time cooperative framework for defending blackouts. Part III: optimization and coordination of defenselines. Automat Electr Power Syst 30(3):1-10 (in Chinese)

[21] Xie Y, Xue Y, Chen J et al (2011) Extensions of power system early-warning defense schemes by integrating wide area meteorological information. In: Proceedings of the 4th international conference on electric utility deregulation and restructuring and power technologies (DRPT'11), Weihai, China, 6-9 July 2011, pp 57-62 (in Chinese)

[22] Xue Y, Fei S, Bu F (2008) Upgrading the blackout defense scheme against extreme disasters. Part I: new challenges and reflection. Automat Electr Power Syst 32(9):1-6 (in Chinese)

[23] Xue Y, Fei S, Bu F (2008) Upgrading the blackout defense scheme against extreme disasters. Part II: tasks and prospects. Automat Electr Power Syst 32(10):1-5 (in Chinese)

[24] Xue Y, Xiao S (2011) Comprehensively defending high risk events with low probability. Automat Electr Power Syst 35(8):1-11 (in Chinese)

[25] Zhao J, Wen F, Xue Y et al (2011) Modeling analysis and control research framework of cyber physical power systems. Automat Electr Power Syst 35(16):1-8 (in Chinese)

[26] Xue Y (2010) Smart grid supporting energy security and environmental safety. Power Syst Clean Energy 26(7):7-11 (in Chinese)

[27] Xue Y, Wang H, Dong $\mathrm{Z}$ et al (2007) A review on restoration control in interconnected grids under electricity market environment. Automat Electr Power Syst 31(21):110-115 (in Chinese)

\section{Author Biographies}

Yusheng XUE (1941-) received PhD in Electrical Engineering from the University of Liege (Belgium) in 1987. He became a Member of Chinese Academy of Engineering in 1995. He is now the Honorary President of State Grid Electric Power Research Institute (SGEPRI). His research interests include nonlinear stability, control and power system automation.

Shijie XIAO (1962-) is a senior engineer and the General Manager of NARI Group Corporation. He is also the President of State Grid Electric Power Research Institute (SGEPRI). His research area is power system and its automation. 